\title{
Prevalence of asthma and related factors in primary school children in an industrial part of England
}

\author{
C D Singleton, A C Gatrell, J Briggs
}

In the UK around $10-12 \%$ of schoolchildren and around $6-10 \%$ of adults have asthma. In any year, at least one in 10 school children will experience symptoms of wheezing. $\mathrm{Ci}$ garette smoke is a major respiratory irritant and damp and mould in homes can precipitate asthma. ${ }^{1}$ Recently, the association between air pollution and respiratory disease has become topical. The pollutants associated most frequently with respiratory health problems are sulphur dioxide $\left(\mathrm{SO}_{2}\right.$ - produced during the burning of fossil fuels and from car exhausts), ${ }^{2}$ ozone, and small particulates. ${ }^{3}$ An association between levels of traffic pollutants, traffic density, and increased levels of childhood asthma has been shown. ${ }^{4}$

Methods: For two years there had been concern expressed by schools and parents in the eastern industrial part of north Derbyshire over a perceived high level of asthma in primary school age children. Interest focussed on three large local industrial sites, including a coking plant, and their pollutant effects on those resident nearby. A cross sectional prevalence survey, using a previously validated ${ }^{56}$ parentcompleted questionnaire of the experience of asthma and wheeze in primary school children from 10 schools over a three month period, was performed to establish whether the level of asthma in these children was higher near these large industrial sites and to attempt to identify any other related environmental factors. Postcode data were collected for each respondent, enabling locational analysis of data, and each postcode was assigned to a grid reference with a precision of 100 metres. Other data collected related to the indoor environment, including physical factors such as overcrowding, double glazing, type of heating, pets, and parental smoking.

7 Epidemiol Community Healt 1995;49:326-327
Results: The total sample was 2133 pupils aged 4-11 years old. Overall, of the 1379 $(64 \cdot 7 \%)$ replies, $237(17 \cdot 1 \%)$ children reported having asthma and an additional $148(10 \cdot 7 \%)$ wheeze. Boys suffered more than girls and analysis by single year age showed a significant excess of wheeze in younger children $\left(\chi^{2} 13.48\right.$, $\mathrm{p}<0.05)$. Results by school are given in the table.

Separate logistic regression analyses of reported episodes of both asthma and wheeze were performed according to the standard technique and examined all possible variables including smoking in the home. These produced the following results:

\section{Asthma model:}

- Solid fuel fire Odds ratio $(\mathrm{OR})=1.935$, (95\% confidence interval (CI) $1.060,3.531$ )

\section{- Open fire $\mathrm{OR}=0.568(95 \%$ CI 0.334 $0.964)$ \\ - Gender $\mathrm{OR}=0 \cdot 708(95 \%$ CI 0.526 , 0.954)}

This shows that the presence of a solid fuel (Parkray) fire had a significant positive effect on asthma prevalence, as did male gender, but that an open fire had a negative effect.

\section{Wheeze model:}

\section{- Mould}

$\mathrm{OR}=2 \cdot 330(95 \%$ CI $1 \cdot 277$, 4.253)

- Ducted air OR=4.059 (95\% CI 1.027, heating 16.038)

- Age $\mathrm{OR}=0.904(95 \%$ CI 0.831 , $0.983)$

- Gender OR=0.656 (95\% CI 0.459, $0.938)$

This shows the positive effects of male gender, of the presence of mould in the home, and of ducted air central heating and shows the magnitude of the age effect discussed above.

Geographical location analysis using IDRISI, a computer based geographical information system, showed a consistent trend with children with asthma living closer to the large industrial sites and a busy trunk road than children without asthma. The prevalence of asthma was statistically significantly greater in children living within a $1-2 \mathrm{~km}$ band from the coking plant (Student's $t$-test, $\mathrm{p}=0.014$ ).

Discussion: This study showed high levels of asthma in young children in the area. The significant negative effect of open coal fires
Minimum prevalence - assuming all non-responders are not asthmatic or not wheezy. + School has large industrial site or an A class trunk road in catchment area. 
on asthma prevalence, despite small numbers $(n=158)$, contradicts published findings for this factor but has been studied little.? There has been no mention of the effect of solid fuel fires on asthma in the published reports but in this study a positive association was shown. The significant positive relationship between ducted air heating and wheeze also needs further investigation to confirm the findings of this study. It is important to continue to press for monitoring of and action to reduce air pollutants in relation to the increasing traffic and pollution problems at a time when asthma prevalence is increasing.
1 Strachan DP, Sanders CH. Damp housing and childhood asthma: respiratory effects of indoor air temperature and relative humidity. 7 Epidemiol Community Health $1989 ; 43$ : $7-14$.

2 Fruedenthal PC, Roth HD, Hammerstrom T, et al. Health risks of short-term $\mathrm{SO}_{2}$ exposure to exercising asthmatics. risks of short-term $\mathrm{SO}_{2}$ exposure to exercising asthmatics. Journal

3 Perry GB, Chai H, Dickey DW, et al. Effect of particulate air pollution on asthmatics. Am $\mathcal{F}$ Public Health 1983;73(1):

4 Walters S. Air pollution and respiratory disease. Proceedings of the Royal Society of Medicine Conference 1992. London: Royal Society of Medicine, 1992.

5 Kingham S. Air pollution and respiratory health in Preston a GIS approach. Lancaster: Lancaster University, 1993. Thesis.

6 Alexander L. The leisure activities and health of primary school children in coastal Lancashire. Report no. 2. Lancaster: Environmental Epidemiology Research Unit, Lancaster University, 1990.

7 Burr ML, St Leger AS, Yarnell JWG. Wheezing, dampness, and coal fires. Community Med 1981;3:205-9.

\title{
Social network and lifestyle in Danish adults
}

\author{
Merete Osler
}

Several prospective studies have associated restricted social network with increased mortality and morbidity, and have increased interest in the possible relations between social network and lifestyle. ${ }^{1-3}$ This study analyses associations between social network and lifestyle - in this case leisure activity, smoking, and the intake of vegetables.

Methods: Data were collected by questionnaire in 1987-88 in a five year follow up study of a random sample $(n=3608)$ of men and women aged $35,45,55$, and 65 years, and living in the County of Copenhagen, Denmark. A total of 2987 participated in the study. Additional information on non-participation and the method of data collection have been reported elsewhere. ${ }^{4}$ Both subjectively perceived and more objective aspects of social network were measured by six variables: (1) contact frequency with family or (2) with friends, neighbours, and relatives; (3) involvement in community activities; (4) marital status; (5) emotional support reflecting the opportunity for talking to intimate relatives and friends about personal matters; and (6) social support describing the person's satisfaction with access to social support when feeling lonely.

Odds ratios (OR) and $95 \%$ confidence intervals $(95 \% \mathrm{CI})$ were calculated to investigate the associations between lifestyle and social network. Because both social network and lifestyle varied with age and social class, ${ }^{4}$ these two variables were treated as covariates. Only minor changes of the associations were noted, however, and the unadjusted ORs are presented.

Results: The prevalence of no leisure activity, smoking, and no daily intake of vegetables in relation to social network is shown in the table. In both men and women, the prevalence of no leisure activity was higher in those with infrequent social contacts with friends or those who experienced little social support than in more socially integrated groups. Men living alone or who reported little emotional support were also more often inactive during leisure time. In women, smoking prevalence was higher in those with infrequent social contacts and little social or emotional support than in those who were more socially integrated. In men, smoking prevalence was independent of the social network. Men and women with infrequent contact with friends or little social support ate vegetables less frequently than those who were more integrated socially. In men, no daily intake of vegetable was also related to little emotional support or living singly.

Discussion: This study corroborates reported results of new determinants associated with health related behaviour. Compared with socially integrated men, those with few social contacts or little social support were more often inactive during leisure time and did not eat vegetables every day. Women with few contacts with friends and relatives were more often physically inactive or smokers. In the Alameda county study, ${ }^{1}$ men and women with the fewest social connections were more often smokers and physically inactive than those with the greatest number of connections (estimated by a score based on marital status, contact with friends and relatives, church membership, and membership of other groups). Other studies have reported that married women are less likely to be smokers than unmarried women, and in a recent study of elderly Swedish men, aspects of social isolation were associated with 